\title{
Coping the Academic Stress: The Way the Students Dealing with Stress
}

\section{Qorry Aina and Primardiana Hermilia Wijayati}

Universitas Negeri Malang, Malang

Muhammadiyah University of Surakarta JI. A. Yani, Mendungan, Pabelan, Kartasura, Kabupaten Sukoharjo, Jawa Tengah 57162, Indonesia

\section{Abstract}

In the educational setting, academic stress has been obviously seen as one of the vital topic. The broad of academic stress sources and the variety of students' coping strategies emerge as the essential factors in this field. Hence, this study is intended to ascertain the students' causes and coping strategies in concerning the academic stress. A survey method was called for collecting and analyzing the data. Further, two questionnaires were entrusted in grasping the academic stress causes and coping strategies namely perception of academic stress scale (PAS) and brief cope (pldts). The data interpretation affirms that the substantial source of academic stress is the students'

Corresponding Author:

Qorry Aina

ainaqorry01@gmail.com

Received: 23 January 2019

Accepted: 26 February 2019

Published: 17 March 2019

Publishing services provided by

Knowledge E

(c) Qorry Aina and Primardiana Hermilia Wijayati. This article is distributed under the terms of the Creative Commons

Attribution License, which permits unrestricted use and redistribution provided that the original author and source are credited.

Selection and Peer-review under the responsibility of the International Seminar on Language, Education, and Culture Conference Committee. worries about their examinations in which $60 \%$ students admitting this subscale. Simultaneously, the prevalent coping strategies work with the subjects are finding the comfort feeling in spiritual beliefs by praying or meditating (52.6\%) whilst accepting the reality and trying to live with it (52.6\%).

Stress has been one of the most important topics in academic issues. There are many sources of academic stress and the way of students cope the stress may differ. Therefore, this study is aimed to find out the sources of students' academic stress and what they are doing when they are in such condition. A survey method was chosen in collecting and analyzing the data. There are two questionnaires that had been given to the subjects of the study for these purposes. The first questionnaire is Perception of Academic Stress Scale (PAS) which used to analyze the causes of academic stress and the second questionnaire is brief cope (ptlds) which used to analyze the way the students cope their stress. The results showed that the main sources of academic stress is the students' worries about their examinations in which $60 \%$ students are agree with this subscale. Moreover, in dealing with the academic stress, more than half of the students (52.6\%) are frequently used to find the comfort feeling in spiritual beliefs by praying or meditating while accepting the reality and try to live with it (52.6\%). In contrast, there only a very few of the students (5.3\%) are rarely using drugs and alcohol to make themselves feel better.

Keywords: coping academic stress, academic stress, coping strategies, sources of academic stress 
Many psycholinguistic researchers have been accomplished ample of researches in assaying the stress. George and Patrick (2017) stated that the word stress much allied to the increased of cardiovascular diseases, rate of depression, anxiety, and other potentially-life threatening issues to one's mind. Further, some researchers (Vermunt \& Steensman, 2005; Malach-Pines \& Keinan, 2007; Topper, 2007) asserted that the term of stress is vividly linked to the perception on one's incapability in fulfilling the environmental demands (stressors). The prior experts' definitions are in accordance with the observations results at the language teaching program; the lecturers are regularly assigning plentiful tasks that inflicting the students in an excessive demands situation.

The stressors have already been identified by some researchers as the excessive assignments, students' competition between one another, the lack of pocket money, failures in academic achievements (Fairbrother and Warn, 2003), bad relationship between students and students, the students and lecturers and the students and their family or problems in home (Joseph and Henry, 2009). Based on the classroom observation, the graduate students of language teaching program are apparently having these kinds of stressors. They are habitually laid at "competitive atmosphere" in the way that they are predominantly managing to do the assignments individually rather than discuss it with others. On the other hand, Ongori (2007), Awino and Agolla (2008) assert that in institutional level, the stressors are dealing with the overfull lecture rooms, semester system, and inadequate resources. On contrary, the diversity of students' needs, goals and expectation should be the considerable factors that the universities need to execute. Inadequately, some needs, goals and expectations of this research subjects are not utterly obtained. They were dissatisfied with some educational systems they have been through.

Academic stress is one kind of the stress arises in in the academic setting such as schools and universities. Coming out of some chronicle facts above, the stressors of this research subjects are highly correlated to the academic setting so that the stress could be assumed as academic stress. Moreover, Olejnik dan Holschuh (2007) defines academic stress as a respond to the number of tasks that the students have to do. The high amount of the tasks results in the emergence of stress among the students. Furthermore, Alvin (2007) and Gusniarti (2002) states that academic stress as a condition which emerge because of the pressures in facing the academic challenging situation among the students, it is lead the students to have a subjective perception toward the incapability in handling both the environmental demands and the students' actual resources. Thus, the more valid and reliable research need to be carried out for acquiring the exact stressors of the students' academic stress. Hence, one of the aims of this 
research is to apprehend the stressors of academic stress. In attaining this purpose, the researcher employs a PAS (Perception of Academic Stress Scale) questionnaire.

If the stress in term of academic conditions is not well managed, it may evoke the one to resultantly have either positive or negative consequences (Smith, 2002; Tweed et al., 2004; Stevenson and Harper, 2006). One very captivating fact was the higher maturity level of the subjects than those who are in undergraduate school. Additionally, they are used to encounter the stressful condition by properly undertaking the assignments. Furthermore, $\mathrm{Li}, \mathrm{CaO}$ and $\mathrm{Li}$ (2016) determine the stress that render good effects as "eustress" and the stress which has bad effects as "distress". The concept of eustress as the positive stress was established by Selye in 1974. The academic stress may cause in high anxiety as well as the students worrying about fail in the course. Conversely, academic stress may also lead to positive impact as the students become more creative for working under pressure. From the point of view of the students, sometimes we definitely need to be in a situation which is enforcing us for doing something seriously. But the universities need to take the students' stress in academic conditions seriously, because the negative consequences may get worse if it is not being well-handled soon. Therefore, it is important to know what the appropriate ways in dealing with the stress that meet the students' stressors.

The way the students deal with the stress is known as cope. The term of coping is referred to behavioral and cognitive efforts in accomplish the appraisal situation that important in regulating the stress (Lazarus \& Folkman, 1984; Crockett, Iturbide, Stone, McGinley, Reffaelli \& Carlo, 2007). It needs to be highlighted that the stress may not affect all people exactly the same and the differences among the individual takes the crucial role in coping the stress (Carver \& Scheier \& Weintraub, 1989; Yumba, 2008). From the observation, the graduate language teaching students have different responses in dealing with stress. Some of them are becoming really active while others get stuck in their mind. Thus, the students need to know the ways how to cope with stress. By knowing the term of coping with the stress, they will know whether they need and how they can find the medical care, social support and advice of the professionals (Passer \& Smith, 2007). Thus, the second aim of this study is to know what kind of coping strategies that the students choose to use in encountering the stress. The Brief Cope questionnaire was chosen for the sake of this purpose. Additionally, the researchers are interested in knowing the detail information about these topics because the subjects of this study are already in graduate program which usually tend to be more mature in dealing the stress than those who are studying in undergraduate program. Besides, the varieties 
of language education backgrounds of the graduate students of language teaching are making these subjects unique.

\section{Method}

This research is designed by using the survey method. Check \& Schutt (2012) considered this kind of method as getting the information from samples by obtaining their responses to some questions. The subjects of this research are 21 graduate students of Language Teaching study program, Malang State University. They are consisting of 2 men and 19 women with the range of age from about 22 up to 27 years old. In this study, the researchers work on using two questionnaires: PAS (Perception of Academic Stress Scale) questionnaire and Brief Cope (pldts) questionnaire. PAS (Perception of Academic Stress Scale) questionnaire is a psychometrically instrument used to assess the academic stress among university students developed by Dalia Bedewy and Adel Gabriel on 2015. This instrument consists of 18 questions with 3 main subscales: the academic expectations subscale (four items), workload and examinations subscale (eight items), and students' academic self-perceptions subscale (six items). The researchers adapted this instrument by eliminating two questions related to how work may affect the students' academic stress. The elimination is considering to be taken because most of the subjects of this study are not work yet. The second questionnaire is Brief Cope questionnaire which consist of 28 questions related to the way that the students used for coping their stress. This questionnaire developed by Charles S. Carver on 1997 as the brief form of the previous published instrument known as COPE inventory created by Carver, Scheier and Weintraub on 1989. Brief Cope consists of 14 subscales with two items on each subscales, they are active coping, planning, positive reframing, acceptance, humour, religion, using emotional support, using instrumental support, self-distraction, denial, venting, substance use, behavioural disengagement and self-blame. The elimination also took into this instrument as the researchers remove one question about using drugs and alcohol to help them get through such stress condition. The researchers ask the participants to fulfil the two questionnaires through the online documents using Google docs. The links of the document are shared through Whatsapp to one by one participant. Unfortunately, there are only 19 responses out from 21 responses on the brief cope questionnaires; there are two participants who did not complete the questionnaire. Subsequently, the data were analysed in form of percentage that automatically had been gotten from the Google docs. 


\section{Findings and Discussion}

The findings of this research are including the subjects of study's responses on completing the PAS questionnaire and Brief Cope questionnaire through the online documents using Google drive. The results of the responses are presented in from of percentage.

\subsection{Findings of academic stress}

To know the stressors of academic stress, the researchers utilize the PAS questionnaire. The subjects of this research are giving their responses on the given statements by choosing whether they are strongly agree, agree, neutral, disagree or strongly disagree with the statements.

TABLE 1: Perception of Academic Stress Scale.

\begin{tabular}{|c|c|c|c|c|c|}
\hline Items of specifications and the subscale items & $\begin{array}{c}\text { Strongly } \\
\text { Agree }\end{array}$ & Agree & Neutral & Disagree & $\begin{array}{l}\text { Strongly } \\
\text { Disagree }\end{array}$ \\
\hline \multicolumn{6}{|l|}{ Stresses related to academic expectations } \\
\hline $\begin{array}{l}\text { Competition with my peers for grades is quite } \\
\text { intense }\end{array}$ & - & $40 \%$ & $60 \%$ & - & - \\
\hline $\begin{array}{l}\text { My teachers are critical of my academic } \\
\text { performance }\end{array}$ & $15 \%$ & $55 \%$ & $30 \%$ & - & - \\
\hline Teachers have unrealistic expectations of me & - & $25 \%$ & $40 \%$ & $35 \%$ & - \\
\hline $\begin{array}{l}\text { The unrealistic expectations of my parents stresses } \\
\text { me out }\end{array}$ & $10 \%$ & $20 \%$ & $30 \%$ & $30 \%$ & $10 \%$ \\
\hline \multicolumn{6}{|l|}{ Stresses related to faculty work and Examinations } \\
\hline $\begin{array}{l}\text { The time allocated to classes and academic work is } \\
\text { enough }\end{array}$ & $5 \%$ & $55 \%$ & $30 \%$ & $5 \%$ & $5 \%$ \\
\hline The size of the curriculum (workload) is excessive & - & - & $45 \%$ & $50 \%$ & $5 \%$ \\
\hline $\begin{array}{l}\text { I believe that the amount of work assignment is too } \\
\text { much }\end{array}$ & $5 \%$ & $10 \%$ & $40 \%$ & $40 \%$ & $5 \%$ \\
\hline The examination questions are usually difficult & - & $25 \%$ & $65 \%$ & $10 \%$ & - \\
\hline Examination time is short to complete the answers & $10 \%$ & $15 \%$ & $55 \%$ & $20 \%$ & - \\
\hline Examination times are very stressful to me & $5 \%$ & $45 \%$ & $25 \%$ & $25 \%$ & - \\
\hline \multicolumn{6}{|l|}{ Stresses related to students' academic self-perceptions } \\
\hline Am confident that I will be a successful student & $10 \%$ & $65 \%$ & $20 \%$ & $5 \%$ & - \\
\hline $\begin{array}{l}\text { Am confident that I will be successful in my future } \\
\text { career }\end{array}$ & $15 \%$ & $75 \%$ & $10 \%$ & - & - \\
\hline I can make academic decisions easily & - & $20 \%$ & $45 \%$ & $35 \%$ & - \\
\hline I fear failing courses this year & - & $5 \%$ & $35 \%$ & $30 \%$ & $5 \%$ \\
\hline $\begin{array}{l}\text { I think that my worry about examinations is } \\
\text { weakness of character }\end{array}$ & - & $60 \%$ & $20 \%$ & $15 \%$ & $5 \%$ \\
\hline $\begin{array}{l}\text { Even if I pass my exams, am worried about getting } \\
\text { a job }\end{array}$ & $5 \%$ & $35 \%$ & $20 \%$ & $25 \%$ & $15 \%$ \\
\hline
\end{tabular}


From the table above, the stressor of the academic stress is the students' selfperception related with their worry about the examination as their weakness of character because more than half of the respondents are agree with this subscale item (60\%). On the other hand, they are mostly (75\%) confident that they will be success in the future.

\subsection{Findings of coping strategies}

The way the students cope they stress may differ so the more detail instrument should be employed in order to identifying the used coping strategies. The Brief Cope questionnaire is taken into this research for accomplishing the aim of this study; to distinguish the cope strategies used by the subjects of this research. There are 27 statement that need to be respond by the subjects as I haven't been doing this at all (1), I've been doing this a little bit (2), l've been doing this a medium amount (3) and I've been doing this a lot (4). The graduate students respond are also don using the online documents provided by Google doc.

TABLE 2: Brief Cope.

\begin{tabular}{|c|c|c|c|c|}
\hline \multicolumn{5}{|l|}{ Active Coping } \\
\hline $\begin{array}{l}\text { I've been concentrating my efforts on doing something about } \\
\text { the situation I'm in }\end{array}$ & - & $42.1 \%$ & $42.1 \%$ & $15.8 \%$ \\
\hline I've been taking action to try to make the situation better & - & $21.1 \%$ & $36.8 \%$ & $42.1 \%$ \\
\hline \multicolumn{5}{|l|}{ Planning } \\
\hline I've been trying to come up with a strategy about what to do & $5.3 \%$ & $26.3 \%$ & $36.8 \%$ & $31.6 \%$ \\
\hline I've been thinking hard about what steps to take & - & $31.6 \%$ & $42.1 \%$ & $26.3 \%$ \\
\hline \multicolumn{5}{|l|}{ Positive Reframing } \\
\hline $\begin{array}{l}\text { I've been trying to see it in a different light, to make it seem } \\
\text { more positive }\end{array}$ & - & $26.3 \%$ & $36.8 \%$ & $36.8 \%$ \\
\hline I've been looking for something good in what is happening & $5.3 \%$ & $26.3 \%$ & $26.3 \%$ & $42.1 \%$ \\
\hline \multicolumn{5}{|l|}{ Acceptance } \\
\hline $\begin{array}{l}\text { I've been accepting the reality of the fact that it has } \\
\text { happened }\end{array}$ & - & $15.8 \%$ & $31.6 \%$ & $52.6 \%$ \\
\hline I've been learning to live with it & - & $15.8 \%$ & $31.6 \%$ & $52.6 \%$ \\
\hline \multicolumn{5}{|l|}{ Humor } \\
\hline I've been making jokes about it & $10.5 \%$ & $21.1 \%$ & $36.8 \%$ & $31.6 \%$ \\
\hline I've been making fun of the situation & $5.3 \%$ & $26.3 \%$ & $31.6 \%$ & $36.8 \%$ \\
\hline \multicolumn{5}{|l|}{ Religion } \\
\hline $\begin{array}{l}\text { I've been trying to find comfort in my religion or spiritual } \\
\text { beliefs }\end{array}$ & - & $5.3 \%$ & $42.1 \%$ & $52.6 \%$ \\
\hline I've been praying or meditating & - & $10.5 \%$ & $36.8 \%$ & $52.6 \%$ \\
\hline Using Emotional Support & & & & \\
\hline
\end{tabular}




\begin{tabular}{|c|c|c|c|c|}
\hline Items of specifications and the subscale items & 1 & 2 & 3 & 4 \\
\hline I've been getting emotional support from others & $10.5 \%$ & $36.8 \%$ & $31.6 \%$ & $21.1 \%$ \\
\hline I've been getting comfort and understanding from someone & $15.8 \%$ & $26.3 \%$ & $31.6 \%$ & $26.3 \%$ \\
\hline \multicolumn{5}{|l|}{ Using Instrumental Support } \\
\hline $\begin{array}{l}\text { I've been trying to get advice or help from other people } \\
\text { about what to do }\end{array}$ & $5.3 \%$ & $26.3 \%$ & $36.8 \%$ & $31.6 \%$ \\
\hline I've been getting help and advice from other people & $5.3 \%$ & $26.3 \%$ & $36.8 \%$ & $31.6 \%$ \\
\hline \multicolumn{5}{|l|}{ Self-Distraction } \\
\hline $\begin{array}{l}\text { I've been turning to work or other activities to take my mind } \\
\text { off things }\end{array}$ & $5.3 \%$ & $52.6 \%$ & $31.6 \%$ & $10.5 \%$ \\
\hline $\begin{array}{l}\text { I've been doing something to think about it less, such as } \\
\text { going to movies, watching TV, reading, daydreaming, } \\
\text { sleeping, or shopping }\end{array}$ & $5.3 \%$ & $21.1 \%$ & $36.8 \%$ & $36.8 \%$ \\
\hline \multicolumn{5}{|l|}{ Denial } \\
\hline I've been saying to myself "this isn't real" & $52.6 \%$ & $10.5 \%$ & $31.6 \%$ & $5.3 \%$ \\
\hline I've been refusing to believe that it has happened & - & $47.4 \%$ & $47.4 \%$ & $5.2 \%$ \\
\hline \multicolumn{5}{|l|}{ Venting } \\
\hline I've been learning to live with it & - & $15.8 \%$ & $31.6 \%$ & $52.6 \%$ \\
\hline I've been saying things to let my unpleasant feelings escape & $15.8 \%$ & $31.6 \%$ & $36.8 \%$ & $15.8 \%$ \\
\hline \multicolumn{5}{|l|}{ Substance Use } \\
\hline $\begin{array}{l}\text { I've been using alcohol or other drugs to make myself feel } \\
\text { better }\end{array}$ & $94.7 \%$ & $5.3 \%$ & - & - \\
\hline \multicolumn{5}{|l|}{ Behavioral Disengagement } \\
\hline I've been giving up trying to deal with it & $31.6 \%$ & $52.6 \%$ & $15.8 \%$ & - \\
\hline I've been giving up the attempt to cope & $15.8 \%$ & $73.7 \%$ & $10.5 \%$ & - \\
\hline \multicolumn{5}{|l|}{ Self-blame } \\
\hline I've been criticizing myself & $5.3 \%$ & $26.3 \%$ & $31.6 \%$ & $36.8 \%$ \\
\hline I've been blaming myself for things that happened & $10.5 \%$ & $21.1 \%$ & $42.1 \%$ & $26.3 \%$ \\
\hline
\end{tabular}

According to the table 2 , half of the students (52.6\%) are habitually coping with stress by finding comfort in their religion. They are also used to praying or meditating (52.6\%). Besides, they are already accept the situation and try to live with it (52.6\%).

\section{Discussion}

The first aim of this study is to know the stressor of academic stress. The PAS questionnaire used in this study consists of three main subscales: the academic expectations, workload and examinations subscale and students' academic self-perceptions subscale. From the table $1,55 \%$ of the subjects are agreeing with the term that the teachers are critical to their academic performance. In fact, the graduate students of language 
teaching are having lecturers from various language education background; the lecturers are coming from English, German, Arabic and Indonesian language education department. The graduate students of language teaching are also coming from different language education background; English, Mandarin, German and Arabic language education department. These differences resulted in unbalancing expectation and goals between the lecturers and the students. Therefore, in some lectures, the lecturers tend to be really critical on the students' performance without considering out differences. This condition is in accordance to the researchers (Vermunt \& Steensman, 2005; MalachPines \& Keinan, 2007; Topper, 2007) definition about stress as the incapability in completing the tasks demand. Therefore, this condition becomes the subjects' stressor of academic stress related to the academic expectation.

The next subscale of PAS questionnaire is the workload and examinations subscale. According to the table 1, the subscale item of "the time allocated to classes and academic work is enough" is having a quite high agreement from the subjects (55\%). In language teaching program, there are eight lectures with 16 CSC (Credit Semester System) on the first semester and six lectures with 15 CSC on the second semester. The allocation of the lectures on the first and the second semester are quite good by way of the students agree with the term "enough". Thus, in this research the stressor are not dealing with the overfull lecture rooms, semester system, and inadequate resources (Ongori, 2007; Awino and Agolla, 2008). Consequently, $65 \%$ of the subjects are neutral with the term that the examination is difficult to be accomplished. It implies that the examination is fairly difficult to them. However, $45 \%$ of the subjects are agreeing that the examination times are very stressful to them.

The last subscale of PAS questionnaire is students' academic self-perceptions subscale. In this subscale, most of the subject admit that they can be success in their future career (75\%). In fact, some of the subject of this study already started to work before and after they are studying in language teaching program. They already have a certain purpose for their future career. In contrast, the subjects are already recognizing their worries as the weakness of character (60\%). Their worries are frequently increased when they are having final examination, it can be seen from their status and stories on their social media such as Whatsapp and Instagram. They used to express their feeling through their social media in such condition. Moreover, Alvin (2007) and Gusniarti (2002) states that academic stress as a condition which emerge because of the pressures in facing the academic challenging situation among the students, it is lead the students to have a subjective perception toward the incapability of between the environmental demands and the students' actual resources. 
The second aim of this study is to identify the coping strategies that usually used by the students. The Brief Cope questionnaire is uses in assessing this purpose. Brief Cope consists of 14 subscales with two items on each subscales, they are active coping, planning, positive reframing, acceptance, humor, religion, using emotional support, using instrumental support, self-distraction, denial, venting, substance use, behavioral disengagement and self-blame. From the table 2 , on the active coping, the subjects are used to take the action to make the situation better (42.1\%). Even though the subjects are feeling stress and worry about their assignment, they are keeping on trying to do their best. In fact, most of the subjects of this study are always complete the assignment well and on time. This is in line with $\mathrm{Li}, \mathrm{CaO}$ and $\mathrm{Li}$ (2016) state that the stress might result in positive effect namely eustress.

On the planning subscale, the subjects are frequently thinking hard about what steps to do $(42.1 \%)$ and what strategies to use $(36.8 \%)$. The subjects of this study are already in the graduate program that has been experiencing to be in the university before. The subjects' range of age is also on the age which the maturity already took in. Hence, the subjects of this study are already well-planned. From the table 2 , the subjects are habitually looking for something good in what is happening (42.1\%) on the positive reframing subscale. It is related to the planning subscale in case they are well-planned because they are always trying to find the good thing in every situation.

The next subscale is acceptance. The graduate students are already accepting the reality (52.6\%) while trying to live with it (52.6\%). On their free time on the classroom, the students usually discuss or do the assignments. This habitual activity proves that they already live with the reality. Next, the subscale is related to humor. $36.8 \%$ of the subjects are making fun of the situation. The amount of this percentage is quite low. It could be related to the maturity and acceptance factor. As the researchers have stated above, the subjects of this study are already mature and accept the reality that result in the feeling of no need to make fun about the stressful condition they got through.

From the table 2, the next subscale is religion. Half of the subjects (52.6\%) are often to find comfort in the religion by meditating and praying. All of the subjects of this study are Indonesian. Indeed, Indonesian people highly uphold the religious values; they get used to find comfort in their religion. On the using emotional support subscale, both of the subscale items having quite low responses and frequencies; $36.8 \%$ on "I've been getting emotional support from others" with a little frequent on doing it and 31.6\% on "I've been getting comfort and understanding from others" with medium frequent on doing it. Again, the maturity might be the reason of these results. 
Furthermore, using instrumental support subscale with $36.8 \%$ of the subjects is frequently trying to get advice from other people about what to do. The next subscale is self-distraction. $36.8 \%$ of the subjects are get used to do something to think about what the reality less such as watching TV and sleeping. 52.6\% of the subjects of this study are turning to work or doing other activities a little. These results can be seen as a result of they are already accepting the reality on the previous subscale. It is also the reason why they are preferred on doing useful things such as work than watching TV. The next subscale is denial. Half of the subjects (52.6\%) are never say to themselves that what is happening is not real. This result in line with the result on the acceptance subscale which is $52.6 \%$ of the subjects already accepting the reality. Venting is the next subscale. The result shows that $52.6 \%$ of the graduate students of language teaching study program are learning to live with it. This is exactly the same result with the acceptance subscale on the item that they already learning to live with it.

The result in the substance use subscale shows that the subjects of this study are mostly (94.7\%) never use alcohol or other drugs in relieving their stress down. As the result on the religion subscale above, the subjects of this study is used to find comfort in religion so that they will not do any negative things such as use alcohol or any other drugs. The next is behavioral disengagement subscale. Most of the subjects (73.7\%) are ever feel hopeless in coping with stress. This is a high percentage with the low frequency. But, it needs to be kept in mind that they are ever felt to giving up deal with stress. The last subscale is related to self-blame. The results show that $36.5 \%$ of the subjects are often criticizing themselves and $42.1 \%$ of the subjects are frequently blaming themselves to things that happened. It proves the result of the PAS questionnaire on the subscale academic self-perceptions as they realize that worries is the weakness of character.

\section{Conclusions}

In conclusion, the use of PAS questionnaire and Brief Cope questionnaire as the instruments already answer the aims of this research; to know the stressors of the subjects' academic stress and the coping strategies they used in deal with the stress. From the research, the most affected factor of the subjects' academic stress is their worries. Their worries are weakening their character on doing the assignment and coping with stress. Moreover, in coping with the stress, they used to find comfort feeling in their religion. They already learn to live with the stress because of the acceptance of the reality. These subjects of the study are also well-planned in finding the strategies to deal with stress. Nevertheless, they ever feel to give their effort up on coping with stress. The coping 
strategies used by the subjects are in line with the stressor. The main stressor is correlated with the self-perception so that the coping strategies they use to do are related to the self-calmness. This is because coping strategy is crucial in stress-adjustment relation (Crockett, Iturbide, Stone, McGinley, Reffaelli \& Carlo, 2007).

\section{References}

[1] Agolla, J. E. \& Ongori, H. 2009. An Assessment of Academic Stress among Undergraduate: The case of University of Botswana. Educational Research and Review, 4 (2), 063-070.

[2] Alvin, N.O. 2007. Handling Study Stress: Panduan Agar Anda Bisa Belajar Bersama Anak-Anak Anda. Jakarta: Elex Media Komputindo.

[3] Awino, J.O., \& Agolla, J.E. 2008. A quest for sustainable quality assurance measurement for universities: case of study of the University of Botswana. Educational Research Review, 3 (6), 213-218.

[4] Bedelwy, D. \& Gabriel, D. 2015. Examining perceptions of academic stress and its sources among university students: The Perception of Academic Stress Scale. Health Psychology Open, 1-9. doi: 10.1177/2055102915596714

[5] Carver, C. S. (1997). You want to measure coping but your protocol's too long: Consider the Brief COPE. International Journal of Behavioral Medicine, 4, 92100. doi: 10.1207/s15327558ijbm0401_6

[6] Chang K, Lu L. 2007. Characteristics of organizational culture, stressors and wellbeing: The case of Taiwanese organizations, J. Manage. Psychol, 22 (6), 549568. doi: 10.1108/02683940710778431

[7] Check J., \& Schutt R. K. 2012. Research methods in education. CA: Sage Publications.

[8] Chen, C. P. 1999. Professional issues: Common stressors among international college students: Research and Counseling Implications. Journal of College Counseling, 2, 49-65.

[9] Crockett, L. J., Iturbide, M. I., Stone, R. A. T., McGinley, M., Raffaelli, M., Carlo, G. 2007. Acculturative stress, social support, and coping: Relations to psychological adjustment among Mexican American college students. Cultural Diversity and Ethnic MinorityPsychology, 13(4), 347-355. doi: 10.1037/1099-9809.13.4.347

[10] Fairbrother, K. \& Warn, J. 2003. Workplace Dimensions, Stress and Job Satisfaction. J. Managerial Psychol, 18(1), 8-21. doi: 10.1108/02683940310459565

[11] Gusniarti, U. 2002. Hubungan antara Persepsi Siswa terhadap Tuntutan dan Harapan Sekolah dengan Derajad Stres Siswa Sekolah Plus. Jurnal Psikologika, 7, 360-372. 
[12] Guthrie, J.T., Wigfield A., \& You W. 2012. Instructional Contexts for Engagement and Achievement in Reading. In S.L. Christenson, A.L. Reschly \& C. Wylie (Eds.), Handbook of Research on Student Engagement. New York: Springer.

[13] Malach-Pines A, Keinan G. 2007. Stress and burnout in Israel police officers during Palestinian uprising (intifada). Int. J. Stress Manage., 14, 160-174.

[14] Olejnik, S. N. \& Holschuh, J. P. 2007. College rules! How to Study, Survive, and Succeed in College (2nd Edition). New York: Ten Speed Press.

[15] Ongori H. 2007. A review of the literature on employee turnover, African Journal of Business Management, 1 (3), 49-54.

[16] Passer, M.W \& Smith, R.E. 2007. Psychology: The Science of the Mind and Behavior (3rd edition). Mc Graw-Hill International edition.

[17] Pintrich, R. R., \& DeGroot, E. V. 1990. Motivational and self-regulated learning components of classroom academic performance. Journal of Educational Psychology, 82, 33-40.

[18] Roberti, J. W., Harrington, L. N., \& Storch, E. A. 2006. Further psychometric support for the 10-item version of the perceived stress scale. Journal of College Counseling, 9, 135-147.

[19] Selye, H. Md. 1974. Stress without distress. New York: The New Ameri-can Library.

[20] Smith, A. 2002. The scale of perceived occupational stress. Occup. Med. 50, 294-8.

[21] Stevenson, A. \& Harper,S. 2006. Workplace stress and the student learning experience, Qual. Assur. Educ., 14(2), 167-178.

[22] Topper EF. 2007. Stress in the library workplace. New Library World, 11 (12), 561-564.

[23] Tweed, R.G., White, K. \& Lehman, D.R. 2004. Culture, stress, and coping. Internally and externally- targeted control strategies of European Canadians, East Asian Canadians, and Japanese. J. Cross Cult. Psychol., 35, 652-68.

[24] Vermunt, R. \& Steensma, H. 2005. How can justice be used to manage stress in organisations. $\mathrm{NJ}$ : Erlbaum.

[25] Yumba, W. 2008. Academic Stress: A Case of the Undergraduate students. Published Thesis. German: Institutionen för beteendevetenskap och lärande. 